\title{
Corazones partidos Una revaluación de las revueltas pasionales
}

Recibido: 02/09/2020 | Revisado: 24/09/2020 | Aceptado: 13/11/2020 DOI: 10.17230/co-herencia.18.34.2

Jorge Giraldo-Ramírez*

jorgegiraldo@eafit.edu.co

Resumen El estado y su ejército, el partido y su guerrilla, han perdido la capacidad de concentrar y orientar las pasiones populares. La pretensión moderna de desconocer y criminalizar las discordias incendiarias ha pasado de propósito a fracaso. La ira se está liberando de las riendas racionales e institucionales y se va haciendo, a la vez, dispersa, volátil y más violenta. Parece apremiante abordar la comprensión de los impulsos destructivos de las multitudes furibundas. El artículo pretende ilustrar esta encrucijada.

\section{Palabras clave:}

Guerra civil, ira, revuelta, motín, América Latina, thimós.

\section{Broken Hearts: A Reassessment of Passionate Revolts}

\begin{abstract}
The state and its army and the party and its guerrillas have lost the ability to gather and guide popular passions. The modern attempt to ignore and criminalize incendiary discord has moved from having purpose toward failure. Anger is breaking free of rational and institutional reins and, at the same time, is becoming dispersed, volatile, and more violent. Understanding and addressing the destructive impulses of angry mobs is an urgent issue. This article aims to illustrate these crossroads.
\end{abstract}

\section{Keywords:}

Civil war, anger, revolt, mutiny, Latin America, thimós.
* Doctor en Filosofía. Profesor emérito de la Universidad EAFIT, Colombia. ORCID: 0000-00027050-3266 
No sabemos de dónde sacó el general Gerald Templer (18981979) la expresión "guerras por corazones y mentes", acuñada para la campaña del imperio británico contra la insurgencia en la península malaya después del final de la Segunda Guerra Mundial. Su divisa fue: "La respuesta no está en enviar más tropas a la selva, sino en los corazones y las mentes de la población” (Lapping, 1985, p. 174). ${ }^{1}$ ¿Sabía que su imagen estaba fuertemente arraigada en la obra de su coterráneo Thomas Hobbes? ¿Tenía su frase alguna conexión intencional con la teoría de Carl von Clausewitz? Lo que sí sabemos es que la guerra por las mentes y los corazones cobró estatus, desde entonces, tanto entre los teóricos (Walzer, 2004, pp. 31, 52) como entre los militares (McAlexander, 2007).

Hobbes le había atribuido a -o había postulado que- la soberanía debería tener la capacidad de reunir mente y corazón; de modo específico, que la razón y las pasiones de los miembros de una comunidad política debían converger de modo absoluto en el soberano. Para él, de un lado, no hay lugar al disenso público ("va anejo a la soberanía el ser juez de qué opiniones y doctrinas desvían de la paz"); del otro, la soberanía se erige sobre la voluntad de los súbditos de tal modo que las pasiones que alimentan la disensión resulten dominadas (Hobbes, 1994, pp. 150 y ss.).

Si Hobbes piensa en la naturaleza de la soberanía, la ocupación de Clausewitz será su dinámica, la guerra como el mayor movimiento posible del soberano. Clausewitz concibe la guerra como una conjunción de mente y corazón. La mente, repartida funcionalmente en la orientación valorativa de la política y la destreza técnica del ejército; el corazón, asentado en la emotividad de la población (Clausewitz, 2005, p. 33). Ese soberano que absorbe los ímpetus pasionales de la multitud debe retornarlos y encauzarlos ante las exigencias de la contienda bélica.

La versión española de los textos en otros idiomas es responsabilidad del autor de este artículo. 
El problema de Templer era otro: la ruptura de la soberanía propiciada por la rebelión de las poblaciones de Malaca contra el imperio británico; ruptura doble si se tiene en cuenta que a una parte de las fuerzas rebeldes les bastaba la independencia y otra buscaba, además, la instauración de un sistema político y económico diferente, el comunismo maoísta. La mente y el corazón de la población ya no tenían consonancia con el imperio y la única manera de ganar la guerra era tratando de ponerlos de su lado. Templer se convirtió así en uno de los pioneros de la estrategia contrainsurgente contemporánea.

El planteamiento hobbesiano es claramente normativo; el pensador de Malmesbury es taxativo en cuanto a juzgar que quienes piensen y sienten por fuera del ámbito soberano "ya estaban en guerra" (Hobbes, 1994, p. 150). Lo mismo puede decirse del general prusiano, quien justifica su acotamiento a la violencia física "porque no hay una violencia moral fuera de los conceptos del estado y la ley" (Clausewitz, 2005, p. 17). El carácter prescriptivo de la filosofía clausewitziana se hace patente cuando tomamos en cuenta que escribía durante el nacimiento de los ejércitos nacionales y en un país que anhelaba convertirse en estado nacional. Templer estaba ante un problema concreto que ya había presenciado Thomas Edward Lawrence (18881935), cuando este se inmiscuyó en la guerra entre árabes y turcos: no solo el corazón de la gente no estaba del lado de la Mancomunidad, también su propio corazón estaba partido entre el afecto originario por su nación y la emergente simpatía por los hombres del desierto; solo que en Malaca la ruptura afectiva resultó inexorable. ${ }^{2}$

Si la guerra civil es el fracaso de la ilusión de Hobbes y el agotamiento de la prescripción de Clausewitz, la desatadura del elemento afectivo, el desborde pasional de la violencia colectiva es el reto de la fórmula de Templer. No es gratuito que de su lección se hayan nutrido buena parte de los enfoques que, algunas décadas

\footnotetext{
Aquí se usarán indistintamente los términos emociones, afectos, pasiones, sentimientos, a sabiendas de la sofisticación a la que han llegado en este campo la neurociencia, la psicología, las ciencias del comportamiento y la filosofía. Un término filosófico más comprehensivo y, por tanto, ambiguo sería animus, "ordenado a la vis irascibilis", una categoría tomista vinculada "con la acepción contemporánea del término ánimo" (Magnavacca, 2005, p. 82). El animus, en general, está bien establecido en las teorías filosóficas de la guerra.
} 
después, pretendieron desenmarañar la guerra contra el terrorismo (McAlexander, 2007).

A continuación, se pretende esbozar de manera preliminar una perspectiva teórica que permitiría enmarcar las explosiones masivas de furia violenta (a), para terminar exponiendo algunas pautas normativas para enfrentarlas (c); antes de esto (b), una ilustración de cómo se ha tratado en América Latina la violencia colectiva podría ayudar a mostrar la actualidad interpretativa y la precariedad normativa que de estos fenómenos se tiene en el continente. ${ }^{3}$

\section{a. Animus belluae y bancarización de la ira}

Como puede deducirse de los párrafos precedentes, los filósofos de la guerra y estrategas tenían en mente no solo la existencia sino la necesidad del factor emotivo en la guerra; su problema era cómo domesticarlo, cómo someterlo y encauzarlo hacia la dirección general de la contienda armada. El arco temporal que separa a Clausewitz de Templer fija también los extremos del espectro que va desde la guerra regular hasta la violencia desenfrenada de un grupo humano cualquiera contra el enemigo o sus representaciones. Y ese arco indica, a su vez, el grado de dificultad que entraña esa labor de sometimiento de la pasión a la orientación racional.

Tómense tres casos ilustrativos de esta dificultad: los de comienzos de la revolución china (a fines de los años 1920), la revuelta árabe contra el imperio otomano (paralela a la Primera Guerra Mundial) y el ya mencionado de la insurgencia en la península Malaca.

Mientras la ortodoxia comunista se acercaba al fracaso en Shangai, Mao Zedong (1893-1976) exploraba las condiciones para su innovadora teoría militar revolucionaria. En 1927, en su "Informe sobre una investigación del movimiento campesino en Junan", da cuenta de la violencia ejercida por grupos campesinos y polemiza contra los copartidarios que quieren embridar estos desórdenes. El exceso es necesario, "para decirlo con toda franqueza, en todas las

Esta reflexión se enfoca en las expresiones violentas de la ira, de ningún modo se pretende que todas o la mayor parte de manifestaciones de esta emoción sean agresivas físicamente. Un ejemplo reciente de indignación pacífica es el movimiento \#MeToo. 
aldeas se necesita un breve período de terror" (Mao, 1968, pp. 25-26). Su idea era desatar la furia y luego controlarla a través de los órganos del partido y las incipientes unidades del ejército (como se sabe, ese control no se detenía ante el uso de medios despóticos y sanguinarios contra la población).

La fuente teórica, previsible, de Mao es Sunzi (544-496 a. C.). Para el estratega filósofo, indignar a la tropa es el medio crucial para motivar el ataque, y la inculcación de esta pasión es parte de la moral que requiere el ejército. ¿Dónde está el balance? En el general y los altos oficiales; estos, por el contrario, deben conservar la calma, mantener clara su perspectiva y sus planes. No solo tranquilidad, la rectitud moral y el compromiso del comandante con sus subordinados son factores que contribuyen a que los combatientes conserven el orden en medio de la refriega y la exaltación (Sunzi, 2009, pp. 95, 112, 120, 175).

El problema táctico de T. E. Lawrence era más complejo que el de Mao, aunque su objetivo estratégico era más simple: hacer converger la acción de tribus rivales, tratar de mover en una misma dirección a muchedumbres de individuos más que grupos organizados, conservar la motivación sin enfrentar directamente al enemigo, evitar la zozobra ante las bajas propias. Enigmáticamente, concluyó que "el máximo desorden era nuestro equilibrio" (Lawrence, 2011, 266). ${ }^{4}$

La fuente teórica, expresa, de Lawrence es Jenofonte (431-354 a. C.). El militar galés sugiere que la guerra tiene tres elementos: "uno algebraico, uno biológico, un tercero psicológico" (2011, 115). El elemento que denomina psicológico es remitido al concepto

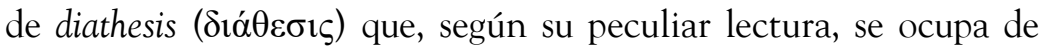
adecuar el espíritu de la multitud para desatarla [exploit], de conducir a los individuos mediante una emoción eficiente [purposeful emotion] y de "preparar las mentes para la batalla", las propias, las del enemigo y las de las naciones enfrentadas (Lawrence, 2011, 165-169). ${ }^{5}$

\footnotetext{
Todas las citas de ediciones Kindle indican la posición, no la página.

Una rica exploración de la diathesis se deriva de la obra de Filodemo de Gadara (11030 a.c.) quien la entiende como una disposición irascible y establece la muy sugestiva diferencia entre ira natural e ira vacía (Blank, 2019). Es conveniente aclarar que la diatética del período helénico incorpora muchos más elementos.
} 
Cuando Templer llegó a la península malaya, en 1951, las autoridades británicas ya se habían percatado del caos que prosiguió al final de la Segunda Guerra Mundial, informado principalmente por el comienzo de hostilidades entre los aliados comunistas y no comunistas y la erosión del dominio colonial. En particular, habían presenciado la sangrienta reacción de los aborígenes malayos contra la violencia ejercida por la guerrilla maoísta y étnicamente china, en un tipo de violencia comunal conocida como amok (Lapping, 1985, p. 161). Amok, de acuerdo con la recepción del término por la Real Academia Española, significa "ataque de locura homicida" y su uso aplicado a la violencia colectiva contemporánea se debe al sociólogo alemán Wolfgang Sofsky (2004). La táctica británica consistió en profundizar las diferencias étnicas en la península entre chinos y malayos (también tailandeses y birmanos) y ayudar a la conformación de una organización política malaya -la United Malayans National Organization- que pudiera hacer frente al partido comunista. Los comunistas fueron derrotados, pero el Reino Unido perdió la península. La furia pudo ser controlada, pero no su resultado. ${ }^{6}$

En un apunte sobre los tipos ideales del animus que podrían atribuirse a las principales categorías de violencia organizada en el marco de las guerras civiles, se había propuesto que a las situaciones polémicas o adversariales corresponde el animus hostis, portado por los estados y los partidos políticos; que el animus belli corresponde a la guerra llevada a cabo por ejércitos y partisanos telúricos; que las nuevas figuras del partisano desincardinado y el terrorista global se caracterizan por el animus belluae; y que, por último, el animus furandi es el rasgo distintivo de piratas y criminales (Giraldo, 2009, p. 135). En los tres casos históricos expuestos antes se pueden apreciar, de manera sumaria, la mezcla de varios animus, su peso relativo distinto y sus modos diferentes de encuadrarlos o inclinarlos a favor de una opción estratégica y racional. Este último aspecto interpela directamente un asunto que podría llamarse "la gestión de la ira".

Conviene anotar que fue una constante del imperialismo británico ver en los rebeldes locales una reacción irracional a la que se calificó como "fanática". Desde entonces hasta la contrainsurgencia actual -no en vano llamada antiterrorista- hay una línea de continuidad (Toscano, 2017, 82). 
Los estados, los partidos políticos, los ejércitos, los guerrilleros de todo tipo (partisanos telúricos) y los partisanos desincardinados tienen todos entre sus funciones la de administrar la ira. Trátese de la abstracta pasión del pueblo, la fuerza motriz de los combatientes, la furia primaria de grupos comunales, la psicología de los generales, la vis irascibilis no puede contarse como una simple externalidad; es un elemento de la guerra que tiene que acotarse y que debe hacer contribuciones relevantes para el balance final. La propaganda, la agitación, los reglamentos, el terror disciplinario son mecanismos usados ancestralmente para cumplir con esa tarea y hacen parte de las artes políticas y militares.

Peter Sloterdijk desnuda la paradoja occidental de que "la primera palabra europea" haya sido ira -según el primer verso de la llíada- y de que el pensamiento occidental -ya desde Platón- se haya alejado de ella (2010, pp. 11, 23). Su poderoso ensayo, Ira y tiempo, se ocupa de ella en las circunstancias del siglo XXI, en un diálogo declarado con la inquietante obra de Francis Fukuyama El fin de la historia y el último hombre (1992), en especial, con la tercera parte. ${ }^{7}$ El punto de partida de ambas reflexiones es el thimós platónico ( $\theta 0 \mu$ ós), pero comenzando la andadura Platón es abandonado. Como se sabe, la solución platónica a los peligros de la fogosidad es el mando racional y estatal (República, 441e). El intelectual estadounidense recrea a su maestro Alexandre Kojève (1902-1968) para fertilizar las ideas de reconocimiento y dignidad, necesarias para sosegar la indignación; el pensador alemán ahonda en la humillación y la dispersión de la ira para terminar, como suele, con insinuaciones trágicas. En este punto solo interesa ahondar en la gestión de la ira.

Sloterdijk esboza tres formas de gestión de la ira a las que llama "venganza" como forma proyectual de la ira, la "revolución" como su forma bancaria y la "religión" como banco metafísico de la venganza (2010, pp. 59-133).

La venganza sería el equivalente a la ira diferida. Al autor de Esferas le basta, para que se pueda considerar como proyecto, que

\footnotetext{
Fukuyama (2019) volvió sobre el tema dos décadas y media después en un libro que toma en cuenta la furia y la violencia colectiva del siglo xxi. Infortunadamente, no se dialoga en este libro con el ensayo del filósofo alemán.
} 
tenga un motivo, un agente y una acción (Sloterdijk, 2010, p. 78). El distanciamiento que caracteriza al vengador lo permea al uso de la razón instrumental, al control del azar y, con ello, lo distancia del recurso a cualquier benjaminiana violencia pura; allí se insertarían el bandolerismo, la autodefensa, el anarquismo o el terrorismo. La analogía bancaria emerge, ya no solo de la contención de la ira, sino de la capacidad de una organización para recogerla, almacenarla; el banco de la ira es un "depósito de explosivos de tipo moral y proyectos de venganza" (Sloterdijk, 2010, p. 79). El bolchevismo y, con mayor catálisis emotiva, el maoísmo, son los ejemplos conspicuos de esta forma de gestión. Las religiones -en este caso, judaísmo y cristianismo- se basan en los recursos exegéticos, teológicos e institucionales que han servido para contener al dios iracundo de las escrituras antiguas. El autor apela al diálogo de Yahvé con Caín, pero hay pocas dudas de que el giro inequívoco, en el cristianismo, se produce con el Sermón de la Montaña cuando se promete que a cambio de soportar el agravio puede obtenerse el cielo (Mateo 5, 11 12), o, también, en el pasaje que invita a abandonar el ojo por ojo y a adoptar la oferta de poner la otra mejilla (Mateo 5, 38-42). ${ }^{8}$

En cualesquiera de las tres formas de gestión de la ira que distingue Sloterdijk, el propósito es ponerle razón a un corazón partido, administrar la ruptura pasional con la unidad política, sea esta imperial o estatal, y orientarla políticamente. Los gestores de la ira -como los tres militares escogidos acá como ejemplo- buscaron convertir ese proceso anímico de despecho en el factor aglutinante para la conformación de un "conjunto thimótico" que pudiera oponerse de forma diáfana con un grupo opuesto que ya no era capaz de conservar los lazos afectivos que lo habían sostenido. Ese es el trasfondo emocional de los polos contestatarios tradicionales como nación, pueblo, clase, partido.

Las diferencias entre las experiencias de administradores como Lawrence, Mao y Templer son de grado, pues reside en las distintas dosis de los componentes de organización, estrategia y pasión,

\footnotetext{
En el presente argumento, esta última forma de gestión se dejará de lado, ya que, como se verá, es menos relevante para el problema en cuestión. Las expresiones milenaristas y pelagianas suelen adoptar la forma bancaria, propia de revoluciones y guerras civiles.
} 
donde siempre la última aparece generosamente. Lo que identifica a los tres es una gestión líquida de la ira. Líquida en el sentido de la metáfora financiera de Sloterdijk, en tanto el ejercicio de la violencia es permanente, prolongado y con amplios márgenes para la acción descentralizada, espontánea y desaforada. No hubo en ellos ahorros de ira, visión incremental de los créditos de la injuria y de los débitos por los cuales el poder dominante debía responder al momento del balance. Esta descripción bancaria es aplicable al esquema leninista mas no al maoísta, por tomar el caso del comunismo. Líquida, también, en el sentido de la metáfora que popularizó Zygmunt Bauman (ya anunciada por Marx, con mejor poesía) y que señala la creciente imposibilidad de controlar las fuerzas liberadas por la modernidad.

Con todo, un incremento cada vez menos improbable de la violencia colectiva desordenada, bajo el signo del animus belluae, es lo que hace que las familias de la taxonomía de Sloterdijk puedan agruparse bajo la clase de violencia gestionada. La razón sigue teniendo en ellas un papel preponderante y de ese modo se conjura el miedo al caos. El historiador judío Flavio Josefo planteó, sin afanes teóricos, las tres posibilidades de la aplicación de la fuerza: señorío, guerra y revuelta, y también observó que ante una situación de señorío insoportable era preferible la segunda opción a la tercera. ${ }^{9}$ El señorío y la guerra están bajo control, producen cierto orden, poseen una teleología identificable; la revuelta, no. El diagnóstico de Sloterdijk parece reducir el panorama a la dicotomía entre señorío o revuelta, puesto que "la ira ha perdido toda forma de coleccionabilidad, transformabilidad y capacidad de configuración" (2010, p. 255). O, dicho de otro modo, la única opción de orden descansa en el señorío -la soberanía, en su traducción moderna; el estado constitucional, en la traducción actual-, pues no habría ya agentes políticos capaces de encuadrar la ira en un proyecto social y de regular el uso de las tecnologías para derramar sangre.

Según la traducción utilizada, la expresión exacta de Josefo sería: "Estando, pues, la ciudad muy trabajada por estas tres cosas, guerra, señorío, revueltas o sediciones, parecióle al pueblo el menor mal de todos estos tres, comparados entre sí, el de la guerra" (1987, p. 43). 


\section{b. Arcaicos, cangaceiros y amotinados, una representación latinoamericana}

El libro de Sloterdijk se publicó en alemán en 2006, y la impresión más cercana del autor estaba formada por el levantamiento de los suburbios parisinos iniciada a fines de 2005, y que todavía continuaba cuando el libro estaba en vitrinas. La edición española se publicó en medio de las protestas globales a que dio pábulo la crisis de 2008 y seguía siendo novedad editorial cuando emergió el movimiento 15-M o de los "indignados".

Sobran razones, de nuevo en la perspectiva de Sloterdijk, para la insurgencia feroz. El desempleo estructural, la frustración del erotismo consumista, la transformación de millones de personas en material desechable, la potenciación de la mímesis propiciada por las nuevas tecnologías, la presión hormonal de los jóvenes sin empleo, ingresos ni mujeres, explicarían el ambiente explosivo. ${ }^{10}$ Si no las hubiera, el hecho palmario es que allí están y no cesan desde 2005 hasta ahora, desde la banlieue hasta Portland 2020, de forma discontinua y ubicua alrededor del mundo. ${ }^{11}$ Pero no parece haber posibilidades para organizar la furia. No existen los partidos que puedan cumplir esa tarea ni teoría en la que puedan afirmarse, los indignados no tienen ni escenarios ni narrativa, la pulsión del consumo hace que el rechazo se reduzca a la simple destrucción, al vandalismo (Sloterdijk, 2010, pp. 246-247). Pensando sólo en la arista violenta del thimós, Sloterdijk deja a un lado la alternativa populista como potencial canal de los insatisfechos y no explora la posibilidad de que tengamos un populismo armado. ${ }^{12}$

El diagnóstico de que la ira había entrado en una fase de

10 Para este último factor, véase el iluminador artículo de Mary Harrington (2020).

11 El escritor indio Pankaj Mishra ha postulado para este tiempo el apelativo de "la era de la ira". Mishra describe una violencia salvaje, endémica, incontrolable y ubicua (2017, 90-96). Falla, sin embargo, en calificarla de "guerra civil global", categoría que Carl Schmitt y Hannah Arendt, entre otros, habían usado para nombrar una lucha con fuertes alinderamientos ideológicos y organizativos.

12 El guionista y director de la película Joker (2019), Todd Phillips, sí lo hace mediante su alegoría del encuentro entre unas masas frenéticas que convierten la impotencia y la desesperación en una ola de violencia sin orden, y una personalidad anómica con un alter ego psicótico. 
dispersión cuenta con dos antecedentes en el norte global, notables por su ocurrencia en medio de la euforia cosmopolita y pacifista. El de Hans Magnus Enzensberger, publicado en 1992 bajo el título de Perspectivas de guerra civil (2016), y el de Robert Kaplan, The Coming Anarchy (1994), que tuvo un mayor impacto en la discusión política y académica. Guerra civil molecular y anarquía, nombres nuevos y viejos para el desorden armado, solo que mientras el pensador alemán discurre sobre fenómenos legibles bajo la microfísica del poder, el periodista estadounidense se ocupa de una prospectiva geopolítica, es decir, macrofísica. El análisis de Sloterdijk, en cambio, se ubica en el terreno meso de las sociedades domésticas en conexión con las internacionales de la rebelión, entablando una conversación más cercana con los estudios sobre la guerra civil.

Así que se puede afirmar que los filósofos y científicos sociales del norte redescubrieron la guerra civil y la revuelta vandálica en la última década del siglo xx. Redescubrimiento como categorías significativas para el análisis social y epocal, y como acontecimientos, en el sentido arendtiano de la palabra. Es decir, predicaron como novedad lo que en América Latina todavía era materia de los estudios del presente. ${ }^{13}$

Cinco años antes del ensayo de Enzensberger, el historiador peruano Alberto Flores Galindo (1949-1990) publicó su libro Buscando un inca en el que investiga las insurgencias indias anteriores a la independencia de España y establece conexiones con la guerra civil protagonizada por Sendero Luminoso en la década de 1980.14

El trabajo de Flores abunda en categorías que se usan distintamente, aunque sin hacer explícitos sus contenidos. Motines espontáneos, locales y cortos; rebeliones (¿menos espontáneas?), regionales y que "logran perturbar la vida económica y social de una región” (1994, p. 99); bandolerismo, sublevaciones y alzamientos, sin más aclaraciones. Penetra más en la distinción entre rebelión

13 Otro ejemplo de los sedicentes descubrimientos del centro está en la observación de Kaplan (2004) de que las guerras posmodernas tienen un gran parecido con las guerras indias y la vitalidad de las reflexiones del militar argentino Lucio Mansilla (2013) sobre las guerras de frontera, publicadas originalmente en 1870.

14 Sendero Luminoso es el nombre con el que se conoce a una de las varias organizaciones que en Perú se llamaron partido comunista y que se convirtió en el principal grupo guerrillero de ese país entre 1980 y 1992. 
y revolución a propósito de los movimientos encabezados por Juan Santos Atahualpa en 1742 y José Gabriel Condorcanqui o Túpac Amaru II en 1780, respectivamente. La rebelión, menos orgánica, compuesta de "personajes desarraigados" (1994, pp. 92-95), con menor impacto en el país; la revolución sostenida por un movimiento social y con objetivos más generales.

Flores, no obstante, encuentra unas continuidades entre ambos, la guerra de independencia -que califica de guerra civil- y la guerra de Sendero Luminoso, que a la luz de nuestro asunto son más relevantes que las diferencias. La primera es la importancia del dominio de las almas y el uso del miedo como sucedáneo de la fuerza militar (Flores, 1994, pp. 66-73). Los indios le otorgaban un carácter religioso a su lucha que se reflejaba en la manera de combatir; los españoles son pischtacos, o sea, "seres infernales" a los que "se les niega la condición de seres humanos", y que por tanto tienen que ser matados de manera diferente (1994, p. 120). Este elemento unificador hace que Flores llame a sus ataques "furores rurales" (p. 104). Por su parte, los españoles calificaron el movimiento de Condorcanqui como insurgente, traidor, apóstata, y le "negaba alguna motivación política" (p. 206). ${ }^{15}$

La segunda continuidad radica en que se trata de revoluciones arcaicas. Nada que ver con la noción de progreso que se adosó al concepto moderno de revolución y definió su especificidad respecto a la noción clásica fijada por Aristóteles y a la propuesta posmoderna de Shmuel Eisendstadt. Los rebeldes indígenas querían restaurar el imperio incaico, buscaban un rey autóctono, una "utopía andina" (Flores, 1994, p. 146). Cosa diferente y significativa es que los criollos que lideraron la independencia y construyeron la república realizaran una operación mitológica integrando simbólicamente las revueltas indias con la guerra contra el imperio español.

Cincuenta años antes de la obra de Flores Galindo y sus furores rurales, el antropólogo Gilberto Freyre (1900-1987) había usado la expresión furor salvaje para referirse al espíritu destructivo de las

15 Explícitamente Flores, que escribía a mediados de la década de 1980, hace la analogía con el calificativo de terrorista para Sendero Luminoso. Citando otras fuentes, inventaría 112 revueltas entre 1730 y 1779 (Flores, 1994, p. 102). 
revueltas brasileras posteriores a la independencia: "raros aquellos de nuestros movimientos políticos o cívicos en los que no hayan ocurrido explosiones de ese furor reprimido o comprimido en tiempos normales" (Freyre, 2013, p. 212).

En especial, durante los años trascurridos entre 1831 y 1844 ocurrieron diversos alzamientos violentos en todo el país. Revueltas como la de balaios, esclavos, presos y campesinos pobres que formaron un ejército de más de once mil hombres; guerras como la de los cabanos, en Pernambuco, que reclutó un número importante de indios y esclavos fugados; saqueos masivos, como los ocurridos en Pará, dirigidos por un bandido apodado Vinagre que dirigía casi un millar de hombres; motines como lo de quebra-quilos, en 1874, contra el sistema métrico decimal y los impuestos.

No hay dudas sobre el desbordamiento de la violencia, con asesinatos y destrucciones indiscriminadas. Hubo, sí, discrepancias valorativas entre las grandes figuras intelectuales del Brasil de la primera mitad del siglo xx. El ensayista Sylvío Roméro (1851-1914) los describió como "movimientos inmensamente anárquicos, inspirados por la ambición, por los malos instintos depredadores de las masas sin educación y sus criminales jefes, los especuladores de políticas alimentarias" (1910, p. 27). Freyre trató de encontrar en algunas sublevaciones atisbos de fervor ideológico, elementos programáticos y capacidad de imponer cierto orden en las acciones armadas. El sociólogo Sérgio Buarque de Holanda (1902-1982) los agrupa como "simples desvíos en la trayectoria de la vida política legal del estado" y no les atribuye un papel significativo en la transformación del país (2009, p. 171). Roméro -el más provocador de los tres- señala a quienes intentan, mediante "efusiones líricas", convertir una "época truculenta" en tiempo de "soberbias virtudes" (1910, p. 28); en una acusación directa contra los publicistas liberales que buscaban insertar estos movimientos en su narrativa.

Casi todas las revueltas fueron tratadas por las autoridades estatales como asuntos de bandoleros, de cangaceiros, y sus protagonistas perseguidos, asesinados o presos. Al parecer, una narrativa republicana o liberal que integrara simbólicamente estos alzamientos no logró imponerse. Los liberales mantenían una "inspiración intelectual" que 
no tenía correlato en las grandes masas ni en una "predisposición espiritual y emotiva" (Buarque, 2009, p. 160).

En el caso colombiano, la unificación material y simbólica de las violencias alrededor de la narrativa de las guerras civiles decimonónicas es más clara que en el siglo XVIII peruano y el siglo XIX brasilero. Solo que, como es ampliamente aceptado en la historiografía, tal unificación no derivó en el fortalecimiento de la idea de una nación sino en la consolidación de las identidades alrededor de dos partidos.

El sociólogo Manuel Alonso -en su estudio sobre la guerra civil de 1859-1862 - muestra cómo se dan, en distintas regiones del país, una serie de levantamientos armados, guerras entre caciques, conflictos privados y odios personales que se mimetizan bajo ropajes políticos y luego se insertan en las configuraciones bélicas entre estados y partidos (2020, p. 190).

El elemento pasional adquiere más relieve en los trabajos del historiador Alonso Valencia Llano sobre quienes denomina "bandidos políticos" (2002, p. 166). Valencia indica que el uso del término "bandido" se utilizó "para designar a quienes eran considerados social y racialmente inferiores y -además- política e ideológicamente contrarios" (2002, p. 160). Muchos de los líderes de estas revueltas habían sido vencidos en guerras precedentes y estaban marcados por la discriminación social y la deshonra. Además, reunían a esclavos prófugos, delincuentes en fuga, remisos a la conscripción militar, vividores de productos ilegales, completando así una identidad social como forajidos. ${ }^{16}$ Cuando se articularon con los bandos que libraban una guerra formal, regional o nacional, lo hacían ostentando su indisciplina y potencia para inducir al terror (Valencia, 2002, p. 158).

La ruptura material y simbólica con las guerras civiles partidistas se inició en el siglo Xx, probablemente, con los levantamientos liderados por el indígena Manuel Quintín Lame. Conscripto por el bando conservador en la Guerra de los Mil Días

16 En el pleno sentido de la palabra se constituyeron en personas fuera de la ley. Valencia recuerda que, en nuestro ámbito, forajido era todo aquel individuo que escapaba del alcance de la ley y la justicia oficiales y construía su propio espacio "afuera del exido" (2002, p. 162). Corripio remite las últimas sílabas al latín exitus, salida, lo que llevaría a un énfasis en el estar fuera. 
(1899-1902), Lame se propuso organizar la lucha indígena por la tierra y la autonomía considerando que la promesa bolivariana de la independencia había sido un engaño (Lemaitre, 2013, p. 305), que los blancos se erigían como sus enemigos y trataban al indio como "ladrón facineroso" (Lame, 1987, p. 31). Su activismo en los departamentos de Cauca y Tolima osciló entre lo que Julieta Lemaitre llama el "legalismo popular" y ataques armados que incluyeron tomas de poblados y choques con la fuerza pública y grupos privados, algunos de ellos también indígenas. Fue señalado por autoridades locales y notables blancos como jefe bandolero, racista e incendiario, juzgado y condenado varias veces por rebelión, asonada, organizador de "motines o tumultos" y de "cuadrillas de malhechores" (Lemaitre, 2013, p. 189).

"La Quintiada" no fue considerada como un movimiento político y siempre se le trató de someter mediante la ley penal. Limitada en sus cotas más violentas a los años 1914-1917 tuvo, sin embargo, una influencia notable en el movimiento social indígena, con sus mingas y disturbios periódicos y en las insurgencias, tanto autodefensivas como ideológicas que surgieron en la década de 1980 en el suroccidente colombiano. ${ }^{17}$

La guerra de mediados de siglo (1946-1953) marcó una ruptura más profunda con la noción de guerra civil por los grados de barbarie, la alta irregularidad de los contendientes y el afán de las dirigencias partidistas de eludir toda responsabilidad en los hechos. En 1950, la dirigencia conservadora encuadró los acontecimientos bajo la interpretación de que se trataba de una violencia bárbara y confusa:

La política subversiva que nuestros adversarios han asumido frente al gobierno, no se enmarca dentro de los moldes generosos y altivos de las guerras civiles del siglo pasado, que recordamos todos como un gesto estremecido de romanticismo y de valor. Es apenas una oscura encrucijada de los delincuentes, que en las sombras asaltan caseríos y veredas para robar e incendiar, mutilar niños, mujeres y ancianos, asesinar y quemar a personas inofensivas. ${ }^{18}$

17 Véase otra referencia a "La Quintiada" y su conexión con las luchas sociales y la emergencia de la guerrilla indígena en los años 1980 (Peñaranda, 2015). Debo la observación sobre la importancia de Lame y su bibliografía al experto Jesús Ramírez Cano.

18 "Declaración de los presidentes de los directorios departamentales conservadores 
Esta interpretación, como se sabe, se impuso. En Colombia esa guerra se conoce popular y académicamente como La violencia. La furia asesina, la violencia ritual, la indiscriminación en el derramamiento de sangre -el terror, en suma- más la opacidad de las jerarquías y la intangibilidad de las organizaciones se enumeraron, entre otras, como razones para no reconocerle su carácter de guerra.

La lectura moderna y eurocéntrica de los movimientos armados y la violencia colectiva en América Latina alcanza su epítome en el intelectual y político boliviano Carlos Montenegro Quiroga (1903-1953). Alborotos, linchamientos, alzamientos, rebeliones, revoluciones, todas son subsumidas por Montenegro bajo la categoría de motines. El motín es un "fenómeno caracterizante de la republicanidad indoamericana" (Montenegro, 1943, p. 55), es el sustrato sempiterno de la política debido a la problemática herencia colonial no resuelta ni por la independencia ni por la república.

En el motín convergen la "obstinación destructora" de un pueblo que vive en estado de "radical descontento" y la "personal ambición de los caudillos" militares o civiles (Montenegro, 1943, pp. 55-59). El afán popular de la protesta encuentra su cauce en los deseos privados de un individuo desvirtuándose así cualquier posibilidad de articular un movimiento nacional auténtico. El mérito no intencional de Montenegro es recuperar el motín para el análisis político, su falla estriba en que toda guerra civil latinoamericana desaparecería bajo la sombra permanente del vínculo espurio entre caudillos y furia popular.

\section{c. Ética y política de la furia amotinada}

Los levantamientos armados que protagonizaron T. E. Lawrence y Mao Zedong, y que combatieron militares académicos como Gerald Templer, fueron excluidos del campo político y normativo por diversas razones. Porque se oponían a la unidad del estado moderno que no admite enemigo interno válido, porque encarnaban

reunidos en la ciudad de Bogotá el $1^{\circ}$ de julio de 1950" (reproducida en Testis Fidelis, 1952, pp. 128-130). Testis Fidelis fue el seudónimo usado por el publicista conservador antioqueño Juan Manuel Saldarriaga. Los libros de Saldarriaga demuestran que tras ese desorden sangriento había un conflicto partidista, religioso y social. 
un tipo de violencia depravada que rebasaba los límites de la organización industrial de la efusión de sangre o, simplemente, porque enarbolaban las banderas de la barbarie ante la cruzada justificada de la civilización. Esta última razón fue muy fuerte entre los positivistas latinoamericanos del siglo XIX y sus herederos del siglo XX para quienes el otro insurgente era bárbaro y suficientemente otro -social, territorial y étnicamente- como para que fuera admisible su reconocimiento como par, así fuera un par enemigo.

Los disturbios violentos en las sociedades industrializadas han sido tratados de manera similar. Para el politólogo Edward C. Banfield suelen reducirse a diversión o ganancia [for fun or profit] (cit. Pasternak, 2019, p. 389); para Enzensberger son una expresión de la "ira contra todo lo que funciona" y "desagrado por lo existente" (2016, p. 253). En las sociedades ordenadas, pacificadas, que han conjurado el espectro de la guerra civil, la violencia callejera, esporádica e intempestiva tampoco tiene un lugar normativo ni político. Es mero caos, exaltación emotiva, destrucción gratuita, vandalismo -la denotación histórica del vándalo no es gratuita-. En gracia de discusión pudiera admitirse, con Sloterdijk, que ha desaparecido toda posibilidad de recolección de la ira y de dirigirla a través de mediadores organizativos y teleológicos de la violencia; pero, aún sobreviven las formas proyectuales de la ira, con sus motivos, sus agentes y sus actos.

Para el amplio rango de formas de gestión de la ira, comprendido entre el disturbio y la guerra civil, Francis Fukuyama sugiere una salida: hay que acoger los elementos positivos del thimós, es decir, el orgullo y la vergüenza $(2019,2.075)$. Esa acogida se produciría alrededor de las comunidades locales y de su integración en grupos mayores hasta llegar al estado nacional. La identidad nacional debe ser el confluente que recoge todas la diversidades culturales, étnicas y estamentales y nadie más que el estado puede garantizar la contención de las fuerzas centrífugas de la sociedad contemporánea. En la identidad y las relaciones de confianza que le subyacen, Fukuyama encuentra el puente entre el elemento pasional civil y el racional institucional; trata de superar el problema de los corazones partidos que mantiene en vela al fantasma de Hobbes. La ampliación y el 
refuerzo de las redes de confianza tienen que contar con una política del reconocimiento y una prioridad a la dignidad de las personas y los grupos sociales que contengan la ira y el resentimiento como los componentes negativos del thimós.

Sloterdijk -cuyas ocupaciones fenoménicas indagan también desde la revuelta callejera hasta la milicia islámica- se mueve en un plano más general, aunque igual de clásico que el de Fukuyama. Hay que hacer todo lo posible por "mantener dentro de sus límites las molestias del hombre por el hombre" (Sloterdijk, 2010, p. 253) y para ello el programa ilustrado sigue dando rendimientos. Pero el idealismo no basta. El pensador alemán entiende que no se puede abandonar la idea humeana del equilibrio de poderes: "Un universo de actores enérgicos, thimóticos e irritables no puede integrarse desde arriba únicamente mediante síntesis ideales, sino sólo a través de unas relaciones fuerza-fuerza que mantengan el equilibrio" (2010, p. 274). Las sociedades democrático-liberales no deben promover la lucha, pero, menos aún, deben evitarla.

Es la profesora israelí Avia Pasternak (2019) quien articula un argumento más minucioso desde el punto de vista normativo y más interesado en conectarse con el discurso filosófico contemporáneo sobre los conflictos armados. También parte de una preocupación más acotada por el disturbio violento, el motín (riot) y lo define como "un desorden público en el que un gran grupo de actores, actuando espontáneamente y sin organización formal, se involucra en actos ilegales y confrontación abierta con las agencias de aplicación de la ley" (2019, p. 388). Aquí es definitiva la especificación de que los actos ilegales incluyen daños a la propiedad, a la integridad física de personas y choques violentos con la policía.

Su punto de partida es la preocupación derivada de que las autoridades de las sociedades democráticas tratan a los revoltosos como delincuentes comunes o incluso peor. Ella intenta demostrar que en la mayoría de los casos se trata de motines de carácter político que comparten los rasgos clásicos de la desobediencia civil, excepto por la nota determinante de que no respetan la autoridad ni la ley y las desafían violentamente (Pasternak, 2019, p. 394). El recurso a la violencia física acerca el motín a la guerra, aunque 
las diferencias no son menores: en el motín se dañan más bienes físicos que personas, es espontáneo, sin comparación posible con los niveles de organización de la guerra, y se trata de una respuesta civil a la injusticia más que a una agresión (Pasternak, 2019, p. 386). Sobre esta base, se apoya en las teorías de la guerra justa para buscar algunos criterios que permitan establecer cuándo se está en presencia de una revuelta justa. ${ }^{19}$

Este tipo de revueltas violentas son políticas en cuanto que (a) se trata de respuestas a injusticias mayores en tipo y escala que no encuentran canales institucionales o participativos para su trámite y resolución; (b) tienen un valor comunicativo que puede lograr que el problema en cuestión sea tenido en cuenta en la agenda pública; (c) tienen un valor moral, en cuanto expresan públicamente la ira y el "sentido del autorrespeto y el orgullo" (Pasternak, 2019, p. 399).

¿Cómo separar a los delincuentes y oportunistas que se involucran en las revueltas pasionales? ¿Cómo aislar a quienes buscan diversión o ganancia? Es un problema planteado sin solución a la vista, si acaso hubiera alguna. La convicción de Pasternak es que "incluso en sociedades democráticas la protesta violenta espontánea puede llegar a ser el único medio disponible para que ciudadanos oprimidos aseguren un rango de metas políticas valiosas" (2019, p. 387).

\section{Lo que viene}

Las expresiones de violencia colectiva -pasionales, desorganizadas, intempestivas, desbordadas- han sido proscritas secularmente como fenómenos que escapan a lo político y a las regulaciones de las guerras civiles. Tal y como se mostró en la sección a), incluso los teóricos de las formas más irregulares de la guerra civil y de una mayor liberación del elemento pasional desarrollaron diversos mecanismos para gestionar la ira. La sección b) ilustró la manera como histórica y conceptualmente se discriminaron y criminalizaron estos fenómenos violentos en América Latina. La sección c) muestra que, en las condiciones actuales,

19 Este aspecto fue ampliamente discutido a raíz de los motines que se desataron bajo la consigna de Black Lives Matter, durante el verano del 2020 en Estados Unidos, pero su análisis escapa a los propósitos de este artículo. 
es importante tratar de comprender qué tipo de inconformidad social subyace a las manifestaciones relativamente espontáneas y violentas; del mismo modo, plantea que esas acciones y sus protagonistas podrían tratarse mediante el uso de criterios análogos a los que se estipulan en la familia de teorías de la guerra justa.

En las tres décadas recientes cobraron ímpetus los estudios sobre la guerra civil y las teorías de la guerra justa. Su andadura todavía será larga, una vez que se comprobó el escaso fuelle de los proyectos del pacifismo cosmopolita. No se deberán limitar a lo que Sloterdijk llama "teorías barbadas" y a sus prácticas; los barbados -guerrilleros, paramilitares, terroristas globales- lucen muy convencionales al lado de los combatientes ocasionales de las revueltas violentas de las metrópolis de todo el mundo. Habrá más pasiones por contrarrestar que teorías por debatir. Los aprendizajes sobre la guerra y la justicia en la guerra deberán ampliar su alcance para cubrir las volátiles y enardecidas expresiones de violencia que son vistas hoy como antipolíticas, aunque lo más probable es que sean ultrapolíticas 【

\section{Referencias}

Alonso, M. (2020). Las formas del campo estatal en el siglo XIX colombiano. Caciques, jefes políticos y desórdenes civiles en la guerra civil de 1859-1862. [Tesis doctoral, Universidad Nacional de Colombia, sede Medellín].

Blank, D. (2019). Philodemus. En E. N. Zalta (Ed.), The Stanford Encyclopedia of Philosophy. https://plato.stanford.edu/archives/spr2019/ entries/philodemus.

Buarque de Holanda, S. (2009). Raízes do Brasil. Companhia das Letras.

Clausewitz, C. von (2005). De la guerra (C. Fortea, Trad.). La esfera de los libros.

Enzensberger, H. M. (2016). Ensayos sobre las discordias (M. Faber-Kaiser, R. Gross y F. Rovira, Trads.). Anagrama.

Flavio Josefo (1987). Guerra de los judíos y destrucción del templo y ciudad de Jerusalén, t. II (J. Martín Cordero, Trad.). Orbis.

Flores Galindo, A. (1994). Buscando un inca: Identidad y utopía en los Andes,

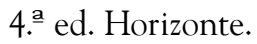


Freyre, G. (2013). Casa-grande EF Senzala. Global Editora.

Fukuyama, F. (2019). Identidad: La demanda de dignidad y las políticas de resentimiento (A. García Maldonado, Trad.). Deusto. (Kindle edition).

Giraldo Ramírez, J. (2009). Guerra civil posmoderna. Siglo del Hombre.

Harrington, M. (2020, junio 25). Incels could become the new Vikings. UnHerd. https://bit.ly/3uaLrw7.

Hobbes, T. (1994). Leviatán (C. Mellizo, Trad.). Altaya.

Kaplan, R. D. (1994, febrero). The Coming Anarchy. The Atlantic. https:/www.theatlantic.com/magazine/archive/1994/02/the-cominganarchy/304670/.

Kaplan, R. D. (2004, septiembre 21). Indian Country. Wall Street Journal, p. A.22. [Versión en línea: https://www.wsj.com/articles/ SB109572689960923141].

Lame, M. Q. (1987). Los pensamientos del indio que se educó dentro de las selvas colombianas. Organización Nacional Indígena de Colombia.

Lapping, B. (1985). End of Empire. St. Martin's Press.

Lawrence, T. E. (2011). The Origin of a Revolt. Praetrorian Press (Kindle edition).

Lemaitre Ripoll, J. (Comp.) (2013). La Quintiada (1912-1925). La rebelión indígena liderada por Manuel Quintín Lame en el Cauca: recopilación de fuentes primarias. Ediciones Uniandes.

Magnavacca, S. (2005). Léxico técnico de filosofía medieval. Universidad de Buenos Aires - Miño y Dávila Editores.

Mansilla, L. V. (2013 [1870]). Una excursión a los indios ranqueles. La Biblioteca Digital.

Mao, Z. (1968). Obras escogidas. Ediciones en Lenguas Extranjeras (Beijing), T. I.

McAlexander, J. C. (2007). Hearts and Minds: Historical Counterinsurgency Lessons to Guide the War of Ideas in the Global War on Terrorism. Air University Press.

Mishra, P. (2017). Age of Anger: A History of the Present. Farrar, Strauss and Giroux (Kindle edition). 
Montenegro Quiroga, C. (1943). Nacionalismo y coloniaje: su expresión histórica en la prensa de Bolivia. Asociación de Periodistas de La Paz.

Pasternak, A. (2019). Political Rioting: A Moral Assesment. Philosophy $\mathcal{E}$ Public Affairs, 46(4), 384-418. https://doi.org/10.1111/papa.12132.

Peñaranda, R. (2015). Guerra propia, guerra ajena. Conflictos armados y reconstrucción identitaria en los Andes colombianos: El Movimiento Armado Quintín Lame. Centro Nacional de Memoria Histórica.

Phillips, T. (Director). (2019). Joker [Película]. DC Films, Village Roadshow Pictures, Bron Creative, Joint Effort Productions and Sikelia Productions.

Platón (1986). República (C. Eggers Lan, Trad.). Gredos.

Roméro, S. (1910). Provocações e Debates: Contribuições para o Estudo do Brazil Social. Livraria Chardron. Repositorio de la Biblioteca Brasiliana Digital. https://digital.bbm.usp.br/handle/bbm/4992.

Sloterdijk, P. (2010). Ira y tiempo (M. Á. Vega y E. Serrano Bertos, Trad.). Siruela.

Sofsky, W. (2004). Tiempos de horror: Amok, violencia, guerra (I. García Adánez, Trad.). Siglo XXI.

Sunzi (2009). El arte de la guerra de Sunzi (L. Ramírez Bellerín, Trad.). La esfera de los libros.

Testis Fidelis (1952). El basilisco en acción o los crímenes del bandolerismo. Granamérica.

Toscano, A. (2017). Fanaticism: On the Uses of an Idea. Verso (Kindle edition).

Valencia Llano, A. (2002). De los bandidos y los políticos caucanos: el General Manuel María Victoria, El Negro. Revista Historia y Espacio, (19), 153-179. https://bit.ly/3sKQT8v.

Walzer, M. (2004). Reflexiones sobre la guerra (C. Castells y C. Casanova, Trads.). Paidós. 


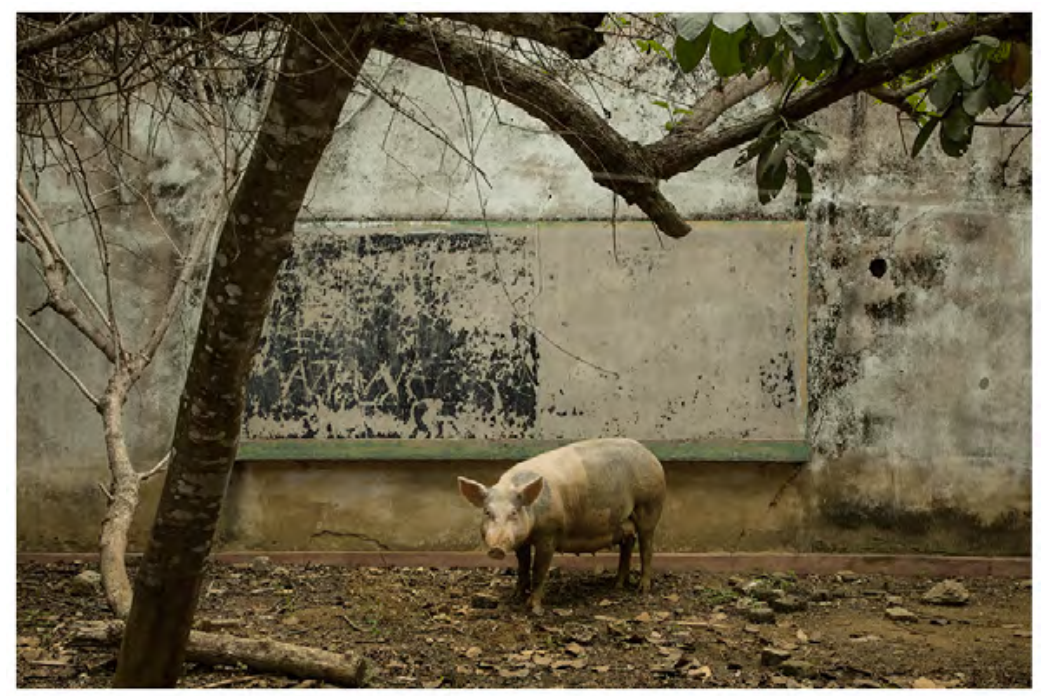

Juan Manuel Echavarría. Testigo La Esperanza. De la serie Silencios. La Esperanza, Bolívar, Colombia. 2013. Fotografía digital c-print. Dimensiones: $101 \times 152 \mathrm{~cm}$. 